\title{
Web Conferencing As Classroom: A New Opportunity In Distance Learning
}

Robert Klonoski, MBA, JD, Mary Baldwin College, USA

With thanks to Rebecca Combs, research assistant.

\begin{abstract}
Web conferencing software enables distance learners to attend classes. This paper recounts student reactions to this delivery method and makes suggestions for conducting virtual classes.
\end{abstract}

Keywords: Virtual classes, Web conferencing, Distance learning

\section{INTRODUCTION}

$\mathrm{n}$ the Adult Degree Program at Mary Baldwin College, classes are offered in a number of formats designed to accommodate the distance learner. Independent classes, which may have had their roots in the more traditional correspondence school format of communicating by "snail" mail, are structured as one-to-one communications between the professor and the student. Online classes are offered through Blackboard a software system commonly used by educational institutions from secondary school through graduate work. Given that many, if not most, of our adult learners are employed full or part time, traditional classes are available during daytime, evening and weekend hours.

Recent developments in software have made a new type of classroom available. Web conferencing software can be licensed from a number of vendors which permit voice and video communication over the Internet along with the display of an application, for example, a Power Point presentation, a spreadsheet, word document, web application or other type of display.

This paper will discuss student usage of and reaction to the software as used in a classroom setting. Students were asked to compare their experiences in the four types of learning formats: Independent, Virtual, Online and Group Classes. Students were asked to rank their experience in terms of their engagement and on several quality factors, to recommend types of courses that would work well in each format, and then to provide overall feedback. Students felt very engaged and felt that they had learned most in the virtual and group formats, with almost equal rankings. Similarly, they were most satisfied with their experience in these two settings. On balance, students saw the virtual class as a functional substitute for an in-person class, while both the online and independent classes engendered far less engagement and satisfaction as an educational experience.

Students were asked to rank the formats they would prefer for certain types of classes: Business Law, Statistics, History of Art, Introduction to Shakespeare, etc. The virtual class format was the most favored, followed by group classes, independent and online options. By asking the question about format in a future class, students were able to put the discomfort of learning the new software behind them and focus more on the benefits and drawbacks of the types of delivery methods.

The groups were then asked to discuss the pros and cons of each type of learning experience and provided the following:

\section{INDEPENDENT STUDY}

The principal benefit of independent study is the flexibility of the schedule. While assignments may be due at fixed times, there is little danger that a late work schedule or a family obligation will interfere with the student's 
ability to find some time at some point to make progress with the assignments. For students who have full time jobs, families and hectic schedules, the flexibility of the independent option can be very compelling.

On the other hand, independent studies were criticized for not being interactive or engaging. The absence of class discussion - both that of professor lecture and student interaction - was sorely felt. Students often felt at a disadvantage for not having participated in the classroom experience and voiced a concern that they had not learned "nearly as much" as they would have in a classroom setting.

On this point, students made three recommendations. One was that professors use the mark-up feature of Word for providing comments on submitted papers. Their feeling was that typed responses placed in appropriate sections of the text would be a more accurate way to provide feedback than notes scribbled in the margins. The second was that lectures can be recorded inexpensively using a web camera and software that is standard on most new computers. While the ability to ask questions in a classroom setting might not be available, the lecture and student interaction can still be seen. The third was that even if software like Blackboard were not to be used, an email group could be set up to promote discussion.

\section{ONLINE STUDY}

Comments were similar for the online version of classes. These classes are offered using Blackboard as the principal communication device. It provides somewhat more interactivity, including a "chat" room for students to ask questions and exchange their comments by email. Other features of the program include the ability to link to resources, and to create exercises and tests.

While students felt that this provided slightly more interactivity than the independent course, neither the independently conducted course not the online course provided the discussion and feedback loop that many students were seeking.

\section{GROUP CLASSES}

This is the traditional classroom setting. Students felt that this was the most engaging and interactive of all the options, but that travel to and from the class consumed precious time. Also, the definite time of the classes often meant that students would have occasional conflicts with work schedules, or be confronted with trouble and expense of arranging for child care.

\section{VIRTUAL CLASSES}

The virtual class served as a hybrid of the online and group class alternatives. Classes met at a definite time, but anyone with a relatively fast internet connection was able to attend the class in virtual space. The software allowed for both voice and video over the internet in a split screen with a presentation, application or other resource. The voice connection was a conference call, so that anyone in the class could speak and be heard by all other participants simultaneously. I should note that my class sizes were typically small - with ten people or less. As a class grows in size, this might become more difficult to manage. The video connection was limited to one person being on screen at a time. The protocol which we set up for the class was that whoever was speaking would be the person to appear on screen. Later versions of the software have multiple video projections, so that the entire class can be seen and heard by all other participants.

Like any new software, it had to be installed and tested by each student who had not used it before. This can be time consuming, depending on the average level of computer savvy in the class. In general, it is easier for upper classmen who have, through their coursework, gotten familiar with Microsoft software, Blackboard, SPSS and other applications. The range on set-up time for the students in my classes was from three minutes to thirty minutes.

This software provided the students with the flexibility of being at home, and consequently not having to be concerned about childcare, or staying in the office to take advantage of superior internet connections. While it did require the students to be available at a specific time, the wide availability of high speed internet connections 
enabled students to have far more mobility than they would for a group class. Students continued to attend class even when on travel, given that many hotels make internet connections available to guests, when on vacation, and during bad weather. Class attendance increased when the weather was inclement. Also, distance was not at issue students were able to attend class, even though several were physically separated from the campus by more than 1,000 miles.

The first class was enough time for nearly all students to become familiar with the software. It is fast to install and easy to use. System problems included an audio echo and feedback, which occurred when students used speakers rather than headphones. A simple adjustment to volume levels was enough to mitigate these difficulties, although the results would likely have been even better had students used headphones.

While the software program we used had many features available - the ability to conduct a poll, to raise a "hand", to draw on the displayed screen, etc., we used rarely used the additional features, and the classes paralleled the way a traditional class would be conducted. As students become more practiced at this format, and as professors become more practiced as well, these additional features may be used more often. One of the professors who used this class to teach an Art Appreciation course encouraged students to draw on a screen or to highlight aspects of a displayed work of art. Students were engaged by this, and after some prompting, used the format quite willingly.

Some students had an initial reticence to being seen on a video screen, similar to a camera shyness some people have for having their pictures taken. Oddly, at the same time students were reluctant to show themselves on screen, they were particularly eager to see the other members of the class. Many of the students who participated in this class had, prior to joining the web class, only taken classes thorough other distance learning options - online and independent classes - and had not had the opportunity to meet other students in their classes. There was a considerable level of curiosity to see who else was in the adult degree program.

In order to overcome this hesitancy, we established a rule in the class that if a person were to speak, the student would have to show him- or herself. Except for one student who had a fear of appearing before a group whether in person or on camera - students overcame this relatively quickly.

\section{PEDAGOGY}

The challenge for educators has always been to find the best way to deliver content in a way that the learner can find value in it. Certain methodologies may be more or less appropriate depending on the type of learning task required of the student. While there are advantages and disadvantages to different methodologies, selecting a taskappropriate technique is critical to achieving an effective learning experience.

When an in-class experience is compared to a distance learning experience, the advantages of the classroom and student-professor as well as student-student interaction are often noted. The absence of an in-class experience made distance learners, on average, feel that they were at a disadvantage when compared with their counterparts who had experienced the student and teacher interaction. Comments received from several of the participants indicated that in the absence of hearing a class lecture and relying only on texts and supplemental materials the tests and evaluations of performance should be adjusted for distance learners. The implication is that the participants felt that their learning experience was less effective precisely because of the lack of interaction. The research conducted here indicated that the most significant advantage of the web conferencing technology is the ability of students to interact in real time with the professor.

When compared with alternative methods, such as the chat room feature available on Blackboard or on other similar resources, the interactive voice communication was rated as the single most important feature of the web conferencing system. The voice-over-internet capability of the system was central to keeping the class focused, especially when group activities were assigned. The key advantage of synchronous interaction is the speed with which feedback and refinement is available to students. Typing into a chat room was not seen as effective as a discussion tool as a conference call voice capability. By interacting live, students realized the efficiency of not having to check a chat room to see if posts had been made in response to their dialogue. 
While asynchronous communications - lectures, records of in-class discussions - would provide the distance learner with the flexibility of listening to a class discussion whenever his or her schedule permits, all but one of the surveyed students felt that the benefit of participating in a live discussion outweighed the disadvantage of having to be in a class on a fixed schedule. The quality of the education being delivered was felt to be so significantly improved that the disadvantage of schedule conflicts was felt to be minimal. The additional inputs of the professor and the interaction of classmates were considered to be significantly important to the learning experience.

\section{BEST PRACTICES}

As of the writing of this paper, web conferencing technology is still in development, and as such, the following may be helpful to the professor interested in using this approach:

1. Have a back-up system. If the voice-over-internet system fails, as happened in one class, the availability of a telephone conference call system would prevent a class cancellation. The quality of sound on a voiceover-internet system is much superior to that on a telephone, and absent a speaker-phone feature, holding a telephone to one's ear for the length of a class can be tiresome, but the new systems are still susceptible to failure.

2. Email the presentation, course materials, class outline, or other notes before each class to all participants. On occasion, the students were unable to access, connect, or download the presentations. This happened while students were on travel and/or away from their regular computers. While this was not typically a problem and was never the fault of the software provider, glitches can and do occur.

3. Pre-test the system before the first class with each student. Alternately, set up the first class as a time to load and test software.

4. Limit the class size. In a classroom or lecture hall, the physical presence of the other students gives all in attendance a visual context that is unavailable on a small screen. While in a classroom, a student can see that another student is getting ready to ask or answer a question; in a voice-only conference call these clues are unavailable.

5. Caution students about what is and is not audible. If students are logging into a class from home and are not using headphones, background noises in one person's environment can be heard by everyone in the class including pets, small children, television sets, etc. The importance of working in a quiet and relatively isolated environment should be emphasized. Similarly, caution students about what is and is not visible in their backgrounds. Any issues should come up in a pre-test of the system.

6. Since the web conferencing software is only available to students who have access to a high speed internet connection (DSL or faster), a small classroom or conference room should be made available to students who would prefer to attend the class in person. A screen and camera can be set up so that the students have the ability to participate online using facilities provided by the school.

7. Have an exercise at the beginning of the class which requires each participant to appear on screen, even if only for a few moments. The reluctance to appear on screen generally dissipates after a student has appeared a few times.

8. Consider offering the online class in conjunction with a physical class. The first class can be used to get students familiar with the software, something which would be easier if it could be physically demonstrated. Assisting a person in setting up software applications remotely can be challenging. If students were to bring in their computers to a place where there is a Wi-Fi connection freely available, the professor can help to get students set up on the system more easily.

9. Also consider the technological savvy of the professors in your school. If your professors are not adept at installing and using software and are unwilling to accept the challenge of trying and testing a new system, there will be several layers of challenges to overcome.

\section{CONCLUSION}

For distance learners, web conferencing presents an opportunity to have a more engaging learning experience than the traditional online and independent learning options. While it is too soon to tell whether in the 
long term the lessons learned in this environment will be more or less memorable than those acquired through other platforms, students did respond positively to the learning environment.

Web conferencing software enables a school to offer a close approximation of a classroom setting to those whose schedules or whose distance might not otherwise be available. As time progresses, and as the software undergoes further development, web-based classes make acquire capabilities not available in a traditional classroom setting. This is a technology which is capable of greatly expanding the reach and quality of distance learning programs.

\section{AUTHOR INFORMATION}

Robert Klonoski is an Assistant Professor of Business Administration at Mary Baldwin College in Virginia, USA. His research interests include Educational Technology and the Social Responsibility of For-Profit and Not-for-Profit Organizations.

Prior to joining Mary Baldwin College, he taught at the University of the District of Columbia, and worked in the financial services industry. Professor Klonoski holds a B.S. in Finance from Fairfield University, an M.B.A. from the University of Connecticut, and a J.D. from Brooklyn Law School.

\section{REFERENCES}

1. Carbonaro M, King S, Taylor E, Satzinger F, Snart F, Drummond J. Integration of e-learning technologies in an interprofessional health science course. Medical Teacher. February 2008; 30(1): 25 - 33.

2. Dondera R, Jia C, Popescu V, Nita-Rotaru C, Dark M, York C. Virtual Classroom Extension for Effective Distance Education. IEEE Computer Graphics \& Applications. January 2008; 28(1): 64 - 74.

3. Grosjean G, Sork T. Going online: Uploading learning to the virtual environment. New Directions for Adult \& Continuing Education. Spring 2007; 113:13-24.

4. Kiefer K. Complexity, class dynamics, and distance learning. Computers \& Composition. March 2006; 23(1): 125-138.

5. Leistyna P, Mollen D. Teaching Social Class through Alternative Media and by Dialoging across Disciplines and Boundaries. Radical Teacher. April 2008; 81: 20-27.

6. Quinn A, Coe Regan J, Schoech D. Online Synchronous Audio and Video Environments for Education, Training and Human Service Delivery: A Review of Three Products. Journal of Technology in Human Services. January 2008; 26(1): 89 - 104.

7. Wu Y, Chen X. A Tool for Assessing Student Learning in Computing Sciences Distance Education Classes. Journal of STEM Education innovations \& Research. January 2008; 9(1): 5 - 12.

8. Yang Z, Liu Q. Research and development of web-based virtual online classroom. Computers \& Education. February 2007; 48(2): 171-184. 


\section{APPENDIX A: SURVEY RESULTS}

1. Was your learning experience greater using the [web conferencing] technology as opposed to a traditional online class (e.g., using Blackboard).

a. Yes $-82 \%$
b. No $-18 \%$

2. What was your level of participation in the class?
a. Extremely high
$9 \%$
b. High
$27 \%$
c. Average
$55 \%$
d. Low
$9 \%$
e. Extremely Low
$0 \%$

3. Do you feel your computer literacy improved as a result of using this technology?
a. Yes
$80 \%$
b. No
$20 \%$

4. Would you feel confident using the [web conferencing] software again?
a. Yes
$73 \%$
b. No
$27 \%$

5. Please rate the quality of the audio:
a. Excellent
$18 \%$
b. Good
$64 \%$
c. Fair
$18 \%$
d. Poor
$0 \%$

6. Please rate the quality of the video:
a. Excellent
$18 \%$
b. Good
$80 \%$
c. Fair
$0 \%$
d. Poor
$0 \%$

7. Please rate the ease of use of the [web conferencing] software:
a. Extremely easy
$27 \%$
b. Somewhat easy
$73 \%$
c. Neutral
$0 \%$
d. Somewhat difficult
$0 \%$
e. Extremely difficult
$0 \%$

8. Please rank the following features $(1=$ most useful, $5=$ least useful $)$
a. Hearing the professor
1.37
b. Seeing the Professor's presentation
1.64
c. Speaking with other students
2.64
d. Seeing the professor
2.82

9. Did having the ability to both see and hear the professor enhance your learning experience?
a. Yes
b. No
$100 \%$
$0 \%$

10. Check any of the items below that apply to web conference classes (versus a Blackboard online class):
a. Made me feel more a part of the class
$82 \%$
b. Made me feel less isolated
$46 \%$
c. Increased my motivation
$46 \%$
d. Increased my participation
$46 \%$ 